\title{
European Respiratory Society guidelines for the diagnosis and management of lymphangioleiomyomatosis
}

\author{
S.R. Johnson*, J.F. Cordier*, R. Lazor, V. Cottin, U. Costabel, S. Harari, \\ M. Reynaud-Gaubert, A. Boehler, M. Brauner, H. Popper, F. Bonetti, \\ C. Kingswood and the Review Panel of the ERS LAM Task Force
}

$\mathbf{L}$

ymphangioleiomyomatosis (LAM) is a rare lung disease, which occurs sporadically or in association with the genetic disease tuberous sclerosis complex (TSC) [1, 2]. Sporadic LAM affects $\sim 1$ in 400,000 adult females; in TSC, LAM occurs in $30-40 \%$ of adult females [3, 4] and exceptionally in males and children $[5,6]$.

Patients with LAM usually develop progressive dyspnoea and recurrent pneumothorax, chylous collections and occasional haemoptysis [1]. Extra pulmonary lymphadenopathy and cystic masses of the axial lymphatics termed lymphangioleiomyomas can result in abdominal and pelvic lymphatic obstruction [7]. LAM is often associated with angiomyolipoma in the kidneys [8], and an increased frequency of meningioma [9]. LAM varies in clinical features and rate of progression: this together with an absence of clear prognostic factors results in patients being given conflicting information about prognosis.

Diagnosis is made by tissue biopsy (generally from the lung but occasionally from lymph nodes or lymphangioleiomyomas) and/or a combination of history and high-resolution computed tomography scanning (HRCT). Pathological diagnosis relies on characteristic LAM cell morphology and positive immunoreactivity to smooth muscle actin and HMB-45 antibodies. Increasingly HRCT is used to diagnose LAM without resorting to lung biopsy; however a number of conditions with multiple pulmonary cysts can mimic LAM.

As LAM is rare, there have been no controlled trials of its management. Supportive treatment includes management of airflow obstruction and hypoxaemia with bronchodilators and oxygen respectively, specific treatment for surgical or pleural complications including pneumo- and chylothorax, and interventional treatment of renal lesions [10,11]. As LAM is a disease of females and is thought to be accelerated by oestrogen, oophorectomy, tamoxifen, progesterone and gonadotropin-releasing hormone $(\mathrm{GnRH})$ analogues have been used without evidence that they are effective. The recent finding of abnormalities in the TSC $1 / 2$ genes resulting in constitutive activation of the kinase mammalian target of rapamycin (mTOR) $[12,13]$ has led to trials of mTOR inhibitors including sirolimus in patients with LAM and angiomyolipoma [14, 15].

\section{METHODS}

The purpose of the LAM Task Force was to produce evidence based, consensus guidelines for the diagnosis, assessment and treatment of patients with LAM. The two Chairmen designed the objectives, obtained European Respiratory Society sponsorship and recruited appropriate specialists. The Core panel had overall responsibility for the development of the guidelines. The Consultant panel advised on specialist aspects. The Review panel reviewed the documents and comprised all members of the Core and Consultant panels plus international experts in LAM, interstitial lung diseases and representatives of European thoracic societies.

The process of guideline development was as follows: 1) question formulation; 2) evidence collection and synthesis (Core and Consultant
KEYWORDS: Angiomyolipoma, chylous effusions, cystic lung disease, lymphangioleiomyomatosis, pneumothorax, tuberous sclerosis

This article has supplementary material accessible from www.erj.ersjournals.com

A longer version of these guidelines incorporating further discussion of the evidence is also available online (www.ersnet.org/ LAMguidelines)

\section{AFFILIATIONS}

*Task Force Co-Chairs.

For affiliations and members of the ERS LAM Task Force Review Panel, please see the Acknowledgements section.

\section{CORRESPONDENCE}

S.R. Johnson

Division of Therapeutics and Molecular Medicine, University of Nottingham

Queens Medical Centre Nottingham. NG7 2UH UK

E-mail: simon.johnson@ nottingham.ac.uk

Received:

May 112009

Accepted after revision:

Aug 242009 
panels); 3) grading of recommendation strength using the 2004 American College of Chest Physicians health and science policy grading system [16] (Core and Consultant panels); 4) formal review with scoring of agreement and proposals for modifications using Likert scale statistics and definitions [17] (Core, Consultant and Review panels); 6) integration of proposals (Core panel); 7) further iterations of the review process with re-assessment of agreement (Core, Consultant and Review panels); and 8) final revision (Core panel). Final recommendations are scored by 1) strength of recommendation: from grade A (strongest) to D (weakest) and I (inconclusive); 2) quality of evidence (quality); 3) magnitude of benefit; and 4) strength of expert consensus. Further details are contained in appendices 1 and 4. A longer version of the guidelines incorporating further discussion of the evidence is also available online (www.ersnet.org/LAMguidelines).

\section{PROPOSED DEFINITIONS AND DIAGNOSTIC WORK-UP FOR LAM \\ Diagnostic criteria}

No studies have been performed which examine the diagnostic accuracy of strategies which do not include lung biopsy (the gold standard for diagnosis in most studies). The diagnostic criteria below result from approaches used by several large series, registries $[3,18-21]$ and expert opinion.

\section{Definite LAM}

1) Characteristic ${ }^{a}$ or compatible ${ }^{a}$ lung HRCT, and lung biopsy fitting the pathological criteria for $\mathrm{LAM}^{\mathrm{a}}$; or

2) Characteristic ${ }^{a}$ lung HRCT and any of the following: angiomyolipoma $(\text { kidney })^{\mathrm{b}}$; thoracic or abdominal chylous effusion $^{\mathrm{c}}$; lymphangioleiomyoma ${ }^{\mathrm{d}}$ or lymph-node involved by $\mathrm{LAM}^{\mathrm{d}}$; and definite or probable TSC ${ }^{\mathrm{e}}$.

\section{Probable LAM}

1) Characteristic ${ }^{a}$ HRCT and compatible clinical history ${ }^{f}$; or

2) Compatible ${ }^{a}$ HRCT and any of the following: angiomyolipoma (kidney) ${ }^{b}$; and thoracic or abdominal chylous effusion ${ }^{c}$.

\section{Possible LAM}

Characteristic $^{\mathrm{a}}$ or compatible $\mathrm{a}^{\mathrm{a}}$ HRCT.

In reference to above text

a) As defined below.

b) Diagnosed by characteristic CT features and/or on pathological examination.

c) Based on visual and/or biochemical characteristics of the effusion.

d) Based on pathological examination.

e) See appendix 2 (available in the online supplementary material; www.erj.ersjournals.com)

f) Compatible clinical features include pneumothorax (especially multiple and/or bilateral) and/or altered lung function tests as in LAM.

\section{Remarks}

1) LAM is considered associated with TSC (TSC-LAM) when TSC is present. Otherwise LAM is considered sporadic.
2) The diagnosis of LAM defined above is only for females. LAM is very exceptional in males without TSC and exceptional in males with TSC where diagnosis requires both characteristic or compatible HRCT and typical pathological features on lung biopsy.

3) The diagnosis of LAM requires exclusion of the alternative causes of cystic lung disease (see online supplementary data p. 18; www.erj.ersjournals.com). A complete diagnostic workup for these alternative causes of cystic lung disease is necessary in patients with probable and especially possible LAM.

Agreement on diagnostic criteria; Consensus: very good.

\section{Pathologic criteria for diagnosis}

Two lesions characterise LAM: cysts and a multifocal nodular proliferation of immature smooth muscle and perivascular epithelioid cells (LAM cells) (fig. 1) [22-24]. Both lesions are found together in variable percentages and the findings may be inconspicuous in early disease. The sensitivity and specificity of the pathological changes seen in LAM have not been addressed. Where a typical proliferation of immature smooth muscle cells and epithelioid cells outside the normal muscular structures occur, associated with cyst formation, routine haematoxylin and eosin staining in combination with adequate clinical and radiological information is sufficient to make the diagnosis in most cases. Immunohistochemistry for smooth muscle actin, desmin and HMB45 is an important adjunct to diagnosis. HMB45 is particularly useful in samples obtained by transbronchial biopsy [25]. In rare cases, HMB45 staining is absent but the characteristic lesions are present and the diagnosis of LAM can still be made $[8,25]$. In such cases correlation with clinical features and CT scan is essential to increase the confidence level of diagnosis. In about half of cases the oestrogen and/or progesterone receptor can be detected by immunohistochemistry [26, 27]. Further details concerning diagnostic and molecular pathology are provided in appendix 3 (available in the online supplementary material; www.erj. ersjournals.com).

\section{Recommendations}

1) Pathological samples from patients with suspected LAM (or any diffuse parenchymal lung disease) should be examined by a pathologist experienced in LAM.

2) LAM should be considered when there is a variable predominance of cysts, multifocal, nodular proliferating immature smooth muscle and perivascular epithelioid cells.

3) Immunohistochemistry for $\alpha$-smooth muscle actin and HMB45 should be performed especially where morphologic features do not allow a secure diagnosis to be made. The oestrogen and progesterone receptor may be an adjunct to diagnosis.

Grade: expert opinion/A; Quality: expert opinion; Benefit: substantial; Consensus: very good.

\section{Radiological criteria for diagnosis}

Characteristic features of pulmonary LAM on HRCT

HRCT is the recommended imaging technique for the diagnosis, assessment and follow-up of diffuse infiltrative lung disease 


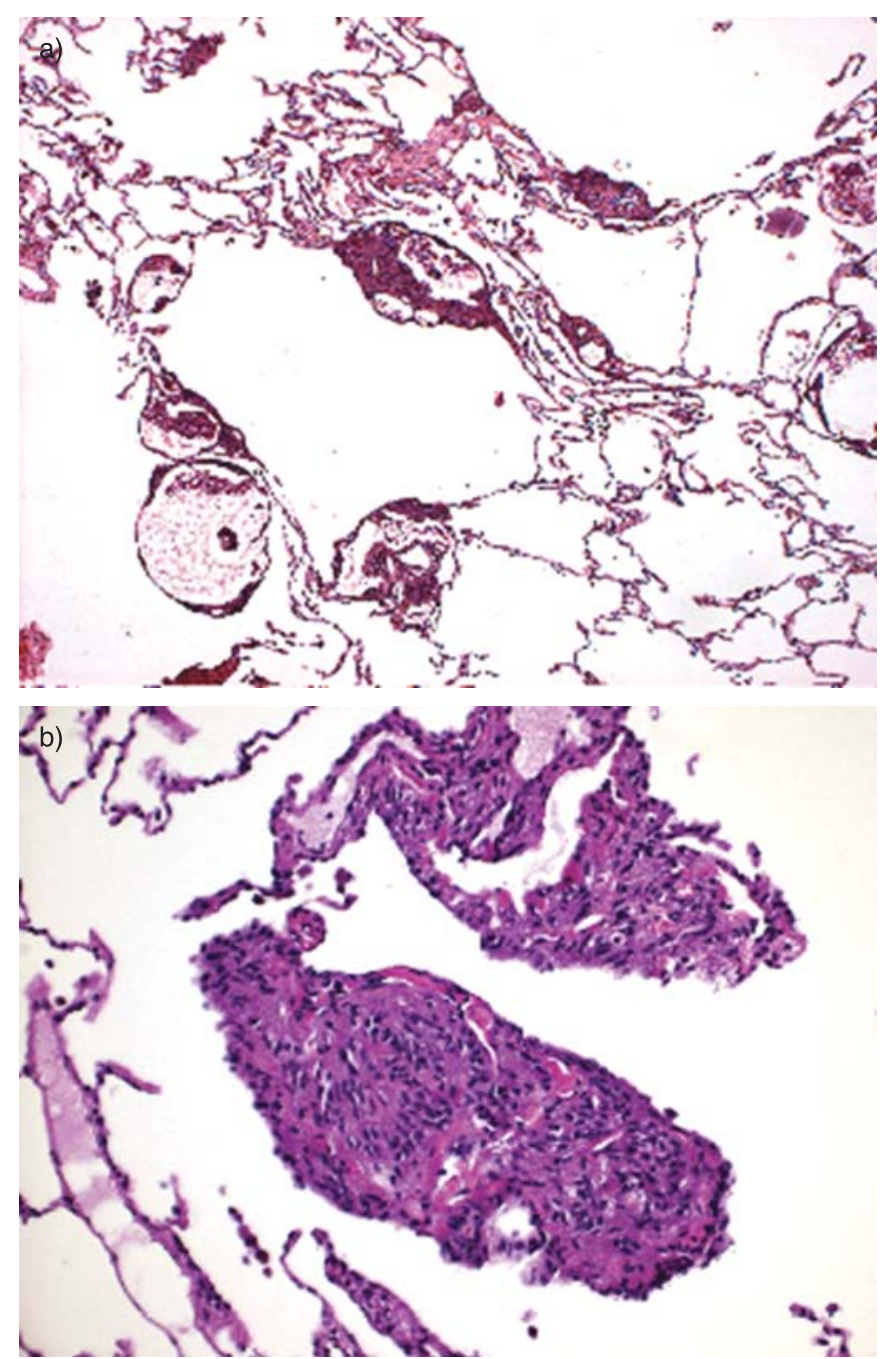

FIGURE 1. Lung biopsies showing proliferating nodules of lymphangioleiomyomatosis cells at low and high power stained with haematoxylin and eosin. Further pathological images are shown in supplementary figure 3 (nww.erj. ersjournals.com).

including LAM [28]. Lung cysts are the hallmark lesion in LAM and are present in all patients (fig. 2) [29, 30]. Their appearance, size and contour vary considerably typically ranging from 2$5 \mathrm{~mm}$ in diameter but occasionally as large as $30 \mathrm{~mm}[31,32]$. Cysts are usually round, distributed evenly throughout the lungs with normal lung parenchyma. Cyst wall thickness ranges from barely perceptible to $2 \mathrm{~mm}$ in most series [32, 33] but has been described as measuring up to $4 \mathrm{~mm}$ [31].

\section{Recommendations}

1) Patients with suspected LAM should have a pulmonary HRCT scan using a thin collimation, high spatial reconstruction algorithm.

2) The acquisition may be performed with sequential scanning (images with $1 \mathrm{~mm}$ collimation at $1-\mathrm{cm}$ intervals) or low dose spiral multidetector CT.

Grade: expert opinion/A; Quality: expert opinion; Benefit: substantial; Consensus: very good.

\section{Remarks}

1) HRCT features characteristic of LAM are multiple $(>10)$ thin-walled round well-defined air-filled cysts with preserved or increased lung volume with no other significant pulmonary involvement specifically no interstitial lung disease with the exception of possible features of multifocal micronodular pneumocyte hyperplasia in patients with TSC.

2) HRCT features are compatible with pulmonary LAM when only few $(>2$ and $\leqslant 10)$ cysts as described are present.

\section{Radiology in abdominal LAM}

Abdominal CT scanning can be used to detect angiomyolipomas, lymphangioleiomyomas or lymphadenopathy to support the diagnosis, to plan the management of angiomyolipomas, and to follow their evolution. Abnormal abdominopelvic imaging findings in patients with LAM are found in up to two thirds of patients [7]. CT is more sensitive and specific than ultrasound and can detect tumours $<1 \mathrm{~cm}$ in diameter [7]. Magnetic resonance imaging (MRI) with and without fat suppression techniques may be adequate for the diagnosis of fat-containing tumours when iodinated contrast is contraindicated [34].

\section{Recommendations}

1) All patients with LAM or suspected LAM should have an abdomino-pelvic CT at diagnosis or during work-up to identify angiomyolipoma and other abdominal lesions.

2) The abdomen should be scanned contiguously with $\leqslant 3 \mathrm{~mm}$ collimation, before and after the intravenous administration of non-ionic contrast.

3) Since a proven therapeutic intervention is not currently available for lymphangioleiomyomas, screening of asymptomatic patients for lymphangioleiomyomas during the course of the disease should not be performed.

4) Patients with abdominal symptoms should be evaluated for the presence of lymphadenopathy or lymphangioleiomyomas by CT scanning.

Grade: C; Quality: low; Benefit: intermediate; Consensus: very good.

\section{Screening for meningioma in patients with sporadic LAM}

Patients with LAM have an increased risk of meningioma [9], the growth of which may be promoted by progesterone. These lesions should be identified especially in patients receiving progesterone. Brain imaging is also useful in the work-up of possible TSC in patients with LAM.

\section{Recommendations}

1) Brain MRI as a baseline evaluation may be useful for comparison during follow-up and should be performed in the presence of symptoms compatible with meningioma. Grade: C; Quality: low; Benefit: intermediate; Consensus: very good.

2) Brain MRI screening for meningioma should be performed in females with LAM receiving progestative drugs or planned to receive such treatment. Grade: expert opinion/B; Quality: expert opinion; Benefit: intermediate; Consensus: very good. 

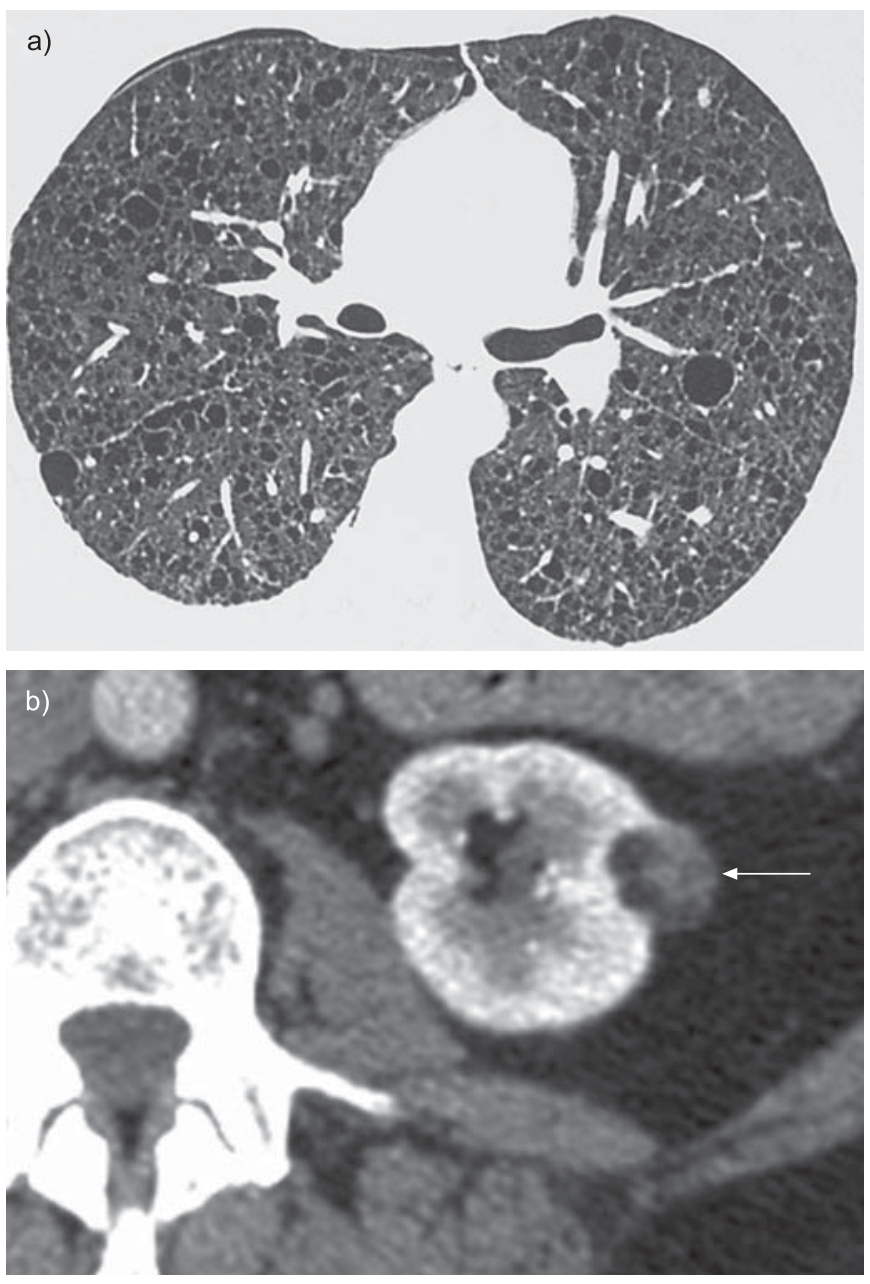

FIGURE 2. (a) High-resolution computed tomography (CT) scan showing typical changes in a patient with moderate lymphangioleiomyomatosis, complicated of a right pneumothorax. (b) CT of an asymptomatic renal angiomyolipoma showing characteristic heterogeneous lesion in the left kidney (arrow). Further lung, renal and abdominal CT images are shown in supplementary figure 2 (www.erj. ersjournals.com)

\section{Work-up for TSC in patients with LAM}

Patients presenting with apparent sporadic LAM may have TSC. As TSC has a highly variable phenotype and two thirds of cases arise as spontaneous mutations the diagnosis can be overlooked. Patients should undergo a full history and physical examination to exclude TSC. Where doubt exists, referral to a clinical geneticist should be made. Diagnostic criteria for TSC and recommendations for assessment of patients are provided in appendix 2 (available in the online supplementary material; www.erj.ersjournals.com) [35].

\section{Recommendations}

1) Patients presenting with LAM should have a thorough personal and family history taken concerning the manifestations of TSC. Physical examination should include the skin, retina and nervous systems by a physician familiar with the manifestations of TSC. Grade: B; Quality: low; Benefit: substantial; Consensus: very good.
2) Patients with LAM and bilateral angiomyolipoma, and other patients where doubt remains, should be referred to a clinical geneticist for full evaluation. Grade: D; Quality: low; Benefit: substantial; Consensus: very good.

3) Routine genetic analysis of patients with sporadic LAM is not of benefit and should not be performed. Grade: D; Quality: low; Benefit: negative; Consensus: very good.

\section{Lung function testing}

Forced expiratory volume in $1 \mathrm{~s}$ (FEV1) and transfer factor of the lung for carbon monoxide $(\mathrm{T} \mathrm{L}, \mathrm{CO})$ correlate with $\mathrm{CT}$ and histological abnormalities in LAM and change over time as the disease progresses $[4,30,36]$. TL,CO, abnormal in more patients than FEV1, may be a more sensitive indicator of early disease. Cardiopulmonary exercise testing may provide additional information especially in patients with milder disease but is more difficult to obtain and perform in a reproducible manner. The rate of decline in FEV1 and $T \mathrm{~L}, \mathrm{CO}$ varies between individuals and it remains difficult to predict the clinical course in individuals and hence how often to repeat lung function. Most physicians initially perform standard lung function tests every 3-6 months. In patients with stable disease, after a period of observation this may be increased to yearly intervals.

\section{Recommendations}

1) Spirometry, bronchodilator testing and TL,CO should be performed in the initial evaluation of patients with LAM (including TSC-LAM). Grade: B; Quality: low; Benefit: substantial; Consensus: very good.

2) FEV1 and TL,CO should be performed to assess disease progression and response to treatment. Grade: B; Quality: low; Benefit: substantial; Consensus: very good.

3) Lung function tests should be repeated every 3-6 month in patients with progressive disease and every 6-12 months in those with more stable disease, as determined by a period of observation of $1 \mathrm{yr}$. Grade: C; Quality: low; Benefit: intermediate; Consensus: very good.

\section{Arterial blood gas measurement}

Arterial hypoxaemia is common in LAM [18, 20, 37]. Blood gases do not provide useful information above that obtained by pulse oximetry in the assessment of patients with mild to moderate disease. However, they provide baseline data and in advanced disease may be useful to define the indication for oxygen therapy, especially for transplant evaluation and to exclude hypercapnia [38].

\section{Recommendations}

1) Blood gases may be performed at initial evaluation of patients with LAM to obtain a baseline value, and in the assessment of patients with severe disease including before transplant referral. Grade: expert opinion/A; Quality: expert opinion; Benefit: substantial; Consensus: very good.

2) Blood gases should be performed to assess the indication for oxygen therapy in patients with advanced disease. Grade: expert opinion/A; Quality: expert opinion; Benefit: substantial; Consensus: very good. 


\section{Cardiopulmonary exercise testing and 6-min walk test}

Exercise performance and maximal oxygen uptake $\left(V^{\prime} \mathrm{O}_{2}, \max \right)$ are impaired in patients with LAM [39]. The 6-min walk test (6MWT) is likely to be helpful in evaluating exercise performance in patients with LAM [40].

\section{Recommendations}

1) Cardiopulmonary exercise testing may be performed to provide additional information over standard lung function tests in symptomatic patients. Grade: C; Quality: low; Benefit: small/weak; Consensus: very good.

2) The 6MWT may be performed in the evaluation of disability, disease progression and response to treatment in symptomatic patients Grade: expert opinion/B; Quality: expert opinion; Benefit: intermediate; Consensus: very good.

\section{Screening for pulmonary hypertension}

Pulmonary hypertension has not been reported frequently in cohorts of patients with LAM [39]. No data are available on the efficacy of treatment of pulmonary hypertension in LAM.

\section{Recommendations}

1) Screening for pulmonary hypertension is not recommended in patients with non-severe LAM. Grade: inconclusive; Quality: low; Benefit: conflicting; Consensus: very good.

2) Estimation of pulmonary artery pressure by echocardiography may be performed in patients with severe disease and those requiring long-term oxygen therapy. Pulmonary artery pressure should be estimated in those considered for lung transplantation. Grade: C; Quality: low; Benefit: intermediate; Consensus: very good.

\section{SCREENING FOR LAM IN AT RISK GROUPS}

Delays between first symptom and diagnosis suggest that in many patients LAM is either not detected for many years or patients are wrongly diagnosed with another disease. Patients may benefit from several low-risk interventions including education on the symptoms of pneumothorax, avoidance of oestrogen containing treatments, prophylactic vaccination against influenza and pneumococcus, smoking cessation measures and monitoring to detect progression at an earlier stage, possibly allowing patients to participate in clinical studies.

\section{Is CT indicated in females with apparently spontaneous pneumothorax?}

The low prevalence of LAM does not justify chest CT for diagnosing LAM for the first pneumothorax. It may be justified for the second pneumothorax, and should be carried out for the third (and more) pneumothorax, especially in nonsmoking females, and if symptoms (e.g. dyspnoea) are present before the pneumothorax.

\section{Recommendations}

1) Chest CT for patients with a first-time pneumothorax should not be performed routinely. Grade: I; Quality: low; Benefit: conflicting; Consensus: good.

2) Chest CT may be indicated to evaluate the presence of LAM that is suspected clinically but is not apparent on standard radiographs. Grade: C; Quality: low; Benefit: small/weak; Consensus: good.

3) The panel did not achieve consensus regarding the utility of chest CT scans for evaluating patients with recurrent pneumothoraces, persistent air leaks, or planned surgical interventions. Grade: I; Quality: low; Benefit: conflicting; Consensus: none.

\section{Should females with TSC undergo screening for LAM by HRCT scan?}

In total, $26-39 \%$ of females with TSC have lung cysts consistent with LAM [2, 41, 42]. Most have no symptoms of lung disease and the natural history of LAM detected by screening in TSC is not known [43]. However detection of LAM in otherwise asymptomatic patients may allow the interventions mentioned previously. As clinical examination, chest radiography and lung function tests may all be normal in the presence of LAM. HRCT is the investigation of choice to detect LAM in these patients.

\section{Recommendations}

1) Females with TSC should undergo screening for LAM by HRCT of the thorax at the age of 18 yrs and if negative again at the age of 30-40 yrs. Grade: C; Quality: low; Benefit: intermediate; Consensus: very good.

2) HRCT should be repeated if persistent respiratory symptoms develop. Grade: C; Quality: low; Benefit: intermediate; Consensus: very good.

3) Females with TSC should undergo HRCT of the thorax in the presence of otherwise unexplained respiratory symptoms. Grade: B; Quality: low; Benefit: substantial; Consensus: very good.

\section{Should males with TSC be screened for LAM by HRCT?}

LAM can occur in males with TSC but is very rare $[5,42,44]$. As males are less likely to be exposed to oestrogen containing treatments early diagnosis of LAM is less likely to be of benefit to patients.

\section{Recommendations}

1) Males with TSC and otherwise unexplained respiratory symptoms should be investigated as dictated by their symptoms; this may include HRCT scanning. Grade: C; Quality: low; Benefit: intermediate; Consensus: very good.

2) Males without respiratory symptoms should not be screened for LAM with HRCT. Grade: D; Quality: low; Benefit: negative; Consensus: very good.

\section{Is screening for LAM needed in females with sporadic angiomyolipoma?}

The prevalence of angiomyolipomas in sporadic LAM is 40 $50 \%$ and $\sim 80 \%$ in TSC-LAM patients when screened by CT [7, 45-47]. In TSC, angiomyolipomas are larger, much more frequently bilateral and more prone to bleeding [48-52].

\section{Recommendations}

1) In patients with unilateral angiomyolipoma, no clinical features of TSC and no pulmonary symptoms, screening for LAM by HRCT may be performed. 
2) In patients with bilateral angiomyolipoma, screening for TSC should be performed, with further LAM screening if TSC is present. Grade: B; Quality: low; Benefit: substantial; Consensus: very good.

\section{PROGNOSIS}

\section{Estimation of prognosis}

Predicting the prognosis of individual patients is difficult. Histological extent of disease [20,23] and some lung function variables [20, 36, 53] have been found to be predictive, at diagnosis, of either survival or more rapid deterioration of lung function. LAM is less severe in TSC-LAM than sporadicLAM although this may reflect ascertainment bias [18, 54]. None of these predictors have been validated prospectively and moreover, some of these variables may only reflect more advanced disease at the time of diagnosis resulting in shorter survival. TL,CO and FEV1 are likely to be the best current indicators of disease progression and survival. Patients with TSC-LAM may have a more indolent course than those with sporadic LAM.

\section{Recommendations}

1) Lung biopsy does not provide prognostic information and should not be performed for this purpose alone. Grade: D; Quality: low; Benefit: negative; Consensus: very good.

2) Disease progression may be evaluated by repeating lung function tests at 3-6 monthly intervals during the first year following diagnosis then at 3-12 monthly intervals depending on the severity and progression of the disease. Grade: C; Quality: low; Benefit: intermediate; Consensus: very good.

\section{Follow-up of patients with TSC-LAM with no pulmonary symptoms}

Sporadic LAM is generally a progressive disease characterised by deteriorating lung function [4, 21]. In patients with TSCLAM and progressive disease regular follow-up and serial lung function is recommended to detect and intervene early where the clinical picture changes. In patients with TSC-LAM and minimal symptoms the risk of severe LAM appears to be lower than in those with sporadic LAM [18].

\section{Recommendations}

1) Regular follow-up by a respiratory specialist or serial lung function studies may not be required for patients with TSCLAM with normal lung function after initial evaluation and who have been stable after a period of observation of $1 \mathrm{yr}$. Follow-up respiratory evaluation and lung function should be performed if respiratory symptoms develop. Grade: expert opinion/C; Quality: expert opinion; Benefit: small/weak; Consensus: very good.

2) Other health professionals involved in the care of patients with TSC and patients themselves should be informed that patients experiencing respiratory symptoms should be seen by a respiratory specialist. This may be in an information document given to patients and general physicians. Grade: expert opinion/C; Quality: expert opinion; Benefit: small/ weak; Consensus: very good.

\section{MANAGEMENT}

\section{General advice and interventions}

In common with other pulmonary diseases, patients with LAM should be encouraged to maintain a normal weight and refrain from smoking. The diagnosis of an orphan disease and its consequences often leave patients with a feeling of isolation. Patient groups can help with these issues and other practical matters.

\section{Advice for patients on pneumothorax}

LAM is associated with an increased risk of pneumothorax which occurs in $\sim 40 \%$ of patients at presentation and $66 \%$ of patients during the course of the disease $[10,55]$. The estimated rate of recurrence after the first episode in LAM is 75\% [29].

\section{Recommendation}

1) Patients with both sporadic and TSC-LAM including those with no or minimal symptoms must be warned of the risk of pneumothorax and told to seek urgent medical attention in the event of symptoms of pneumothorax. Grade: A; Quality: fair; Benefit: substantial; Consensus: very good.

\section{Advice for patients and management of pregnancy}

It is likely that pregnancy in LAM is associated with an increased risk of pneumothorax and chylothorax [10, 56-60]. It is suspected that pregnancy may accelerate the decline in lung function [61]. It is likely that patients with poor baseline lung function are less likely to tolerate a pneumothorax or chylous effusion during pregnancy. There may be an increased risk of bleeding from angiomyolipoma during pregnancy [62-65].

\section{Recommendations}

1) To become pregnant is the patients' decision. However all patients, including those with few or no symptoms, should be informed that there is a greater risk of pneumothorax and chylous effusion during pregnancy. Those with recurrent pneumothorax or effusion outside pregnancy and those with poor baseline lung function are at greater risk during pregnancy. Grade: expert opinion/B; Quality: expert opinion; Benefit: intermediate; Consensus: very good.

2) Females with LAM who are pregnant should receive information, ideally pre-pregnancy or as soon after conception as feasible to warn of the risk of pneumothorax, effusion and bleeding from angiomyolipoma. Grade: expert opinion/B; Quality: expert opinion; Benefit: intermediate; Consensus: very good.

3) Patients with tuberous sclerosis should further receive genetic counselling prior to conception. Grade: A; Quality: good; Benefit: substantial; Consensus: very good.

4) Patients should be monitored during pregnancy by both a pulmonary physician and an obstetrician informed about LAM. Grade: expert opinion/B; Quality: expert opinion; Benefit: intermediate; Consensus: very good.

5) It may be appropriate to discourage patients with severe disease from becoming pregnant, this counsel being given on an individual basis. Grade: expert opinion/B; Quality: expert opinion; Benefit: intermediate; Consensus: very good. 


\section{Avoidance of oestrogen including the contraceptive pill and hormone replacement}

Exogenous oestrogens may promote the progression of pulmonary LAM in at least some cases [66-69].

\section{Recommendation}

1) Females with LAM should avoid oestrogen containing treatments including the combined oral contraceptive pill and hormone replacement therapy. Grade: C; Quality: low; Benefit: intermediate; Consensus: very good.

\section{Information for patients concerning air travel}

Reports of pneumothorax occurring in flight have resulted in females with LAM being advised not to travel by air [70]. Patients with sporadic and TSC-LAM with well preserved lung function do not need to take specific precautions or avoid air travel. Those with advanced disease should be evaluated for the need for oxygen during flight to prevent hypoxaemia and as they are less likely to tolerate pneumothorax.

\section{Recommendations}

1) Patients with sporadic or TSC-LAM and minimal symptoms should not be discouraged from air travel. They should be warned that they should not travel if new respiratory symptoms have not been evaluated. Grade: C; Quality: low; Benefit: intermediate; Consensus: very good.

2) Patients with advanced disease should be evaluated for the need for oxygen during flight and should not travel if new respiratory symptoms have not been evaluated. Those for whom an untreated pneumothorax may have serious consequences should consider alternatives to air travel. Grade: C; Quality: low; Benefit: intermediate; Consensus: very good.

3) Patients with a known untreated pneumothorax, or a pneumothorax treated within the previous month, should not travel by air. Grade: B; Quality: low; Benefit: substantial; Consensus: very good.

\section{Pulmonary rehabilitation}

Although there have been no specific studies examining the impact of pulmonary rehabilitation in LAM, supporting evidence of benefit may be extrapolated from other diseases including chronic obstructive pulmonary disease (COPD) [71].

\section{Recommendation}

1) Pulmonary rehabilitation may be offered to patients with LAM who are limited by dyspnoea. Grade: expert opinion/B; Quality: expert opinion; Benefit: intermediate; Consensus: very good.

\section{Influenza and pneumococcal vaccination}

Although the effect of prophylactic vaccination in patients with LAM has not been tested, by analogy with COPD, it may be proposed to patients with LAM and impaired lung function [72].

\section{Recommendation}

1) Influenza and pneumococcal vaccination should be offered to patients with LAM. Grade: expert opinion/B; Quality: expert opinion; Benefit: intermediate; Consensus: very good.

\section{Assessment and management of osteoporosis}

LAM is associated with reduced bone mineral density in a significant proportion of patients [73]. In view of the rapid deterioration in bone mineral density observed after lung transplantation, early initiation of aggressive therapy in LAM patients with severe lung disease and osteopenia at any bone site is recommended. Weight-bearing exercise and strength training should be encouraged.

\section{Recommendations}

1) Patients with LAM, especially those post-menopause, should undergo periodic evaluation of bone mineral density. Grade: B; Quality: low; Benefit: substantial; Consensus: very good.

2) Those with osteoporosis should be treated the same as other patients with osteoporosis. Grade: B; Quality: low; Benefit: substantial; Consensus: very good.

3) In view of the rapid deterioration in bone mineral density observed after lung transplantation, aggressive therapy for osteoporosis should be initiated early in LAM patients with severe lung disease and osteopenia at any bone site. In addition to pharmacological therapy, weight-bearing exercise and strength training should be encouraged because of the growing evidence that exercise improves bone density. Grade: B; Quality: low; Benefit: substantial; Consensus: very good.

\section{Inhaled bronchodilators}

One quarter of patients respond to inhaled bronchodilators according to standard objective criteria and more may obtain some clinical benefit [8, 36]. Patients who respond to bronchodilators tend to have airflow obstruction and have a greater rate of decline in FEV1. Although bronchiolar inflammation is seen in some patients [36] the efficacy of inhaled corticosteroids in LAM has not been assessed.

\section{Recommendation}

1) Inhaled bronchodilators should be trialled in patients with airflow obstruction and continued if a response is observed. Grade: B; Quality: low; Benefit: substantial; Consensus: very good.

\section{Hormone therapy: progesterone}

There are no randomised placebo controlled trials of progesterone in LAM despite its widespread use [18]. Some case series and reports suggested it to be effective in some patients. However, drawing conclusions from case reports is prone to bias as positive outcomes are more likely to be reported than harmful or ineffective treatments. Similarly, more rapidly declining patients are treated with progesterone. Such studies have shown either no effect or worsening of lung function or dyspnoea in the progesterone treated patients and in one case a nonsustained reduction in rate of decline in $T \mathrm{~L}, \mathrm{CO}[4,21]$.

\section{Recommendations}

1) Oral or intramuscular progesterone should not be used routinely in patients with LAM. Grade: I; Quality: low: Benefit: conflicting; Consensus: very good.

2) In patients with a rapid decline in lung function or symptoms, intramuscular progesterone may be trialled. 
Grade: C; Quality: low; Benefit: small/weak; Consensus: very good.

3) If used, progesterone may be given for 12 months with clinical evaluation and lung function at 3 monthly intervals. If lung function and symptoms continue to decline at the same rate on progesterone treatment after one year, progesterone should be withdrawn. Grade: expert opinion/C; Quality: expert opinion; Benefit: small/weak; Consensus very good.

\section{Hormone therapy: other anti-oestrogen interventions}

Despite a number of case reports describing the use of oophorectomy [74-78], tamoxifen [79-82] and GnRH agonists [83-85] in LAM no confident data exist on the efficacy of any anti-oestrogen strategy for LAM. One recent open label study that examined 11 patients treated with the $\mathrm{GnRH}$ agonist triptorelin found that no patients improved and the drug was associated with a reduction in bone mineral density [86].

\section{Recommendation}

1) Hormone treatments other than progesterone should not be used in patients with LAM. Grade: I; Quality: low; Benefit: conflicting; Consensus: very good.

\section{mTOR inhibitors}

Inherited mutations of the TSC-1 or TSC-2 genes cause TSC while acquired (somatic) mutations of either gene are associated with sporadic LAM. The mTOR pathway is constitutively activated in LAM [12, 13]. Two prospective open-label clinical trials suggest that the mTOR inhibitor sirolimus reduces angiomyolipoma volume [14, 15]. However, the effect on bleeding from angiomyolipomas has not been evaluated. Furthermore, the relative risk/benefit of treatment has not been compared with that of other established treatments of angiomyolipoma (i.e. catheter embolisation and conservative surgery). The effect of mTOR inhibitors on pulmonary function is unclear and their use can be associated with adverse events. mTOR inhibitors may be a future therapeutic option in patients with LAM and further studies are required.

\section{Recommendations}

1) Sirolimus should not be prescribed routinely outside clinical trials for pulmonary LAM. Patients with LAM should be encouraged to participate in clinical trials whenever possible. Grade: C; Quality: low; Benefit: small/weak; Consensus: very good.

2) In renal angiomyolipoma mTOR inhibitors should not be used as first-line therapy. Sirolimus may be considered on an individual basis in patients with symptomatic angiomyolipoma or LAM-related masses not amenable to embolisation or conservative surgery in experienced centres. Grade: C; Quality: low; Benefit: small/weak; Consensus: very good.

3) In the current context of scientific uncertainty but possible treatment benefit, sirolimus may be considered on an individual basis in patients with rapid decline in lung function or symptoms, after careful evaluation of risk/benefit ratio in an experienced centre. When sirolimus is used, the effect of therapy should be carefully monitored for tolerance and effect on lung function at 3 monthly intervals. Sirolimus should be stopped once patients are listed for active lung transplantation. Grade: C; Quality: low; Benefit: small/weak; Consensus: very good.

\section{COMPLICATIONS AND CO-MORBIDITIES \\ Management of pneumothorax}

Pneumothorax occurs in the majority of patients, results in significant hospital stays, and is frequently recurrent. Conservative treatments are associated with higher rates of recurrence than pleurodesis via chest tube or appropriate surgical interventions $[10,55]$. Lung transplantation in patients with previous thoracic surgery or pleural procedures may be associated with increased technical difficulty and an increased risk or perioperative bleeding $[38,55,87,88]$.

\section{Recommendations}

1) Pneumothorax in LAM should ideally be managed jointly by a chest physician and thoracic surgeon. Grade: C; Quality: low; Benefit: intermediate; Consensus: very good.

2) Chemical pleurodesis may be performed at first pneumothorax. Patients who do not respond to initial therapy including pleurodesis, should undergo an appropriate surgical procedure according to their clinical condition and local expertise. Grade: C; Quality: low; Benefit: intermediate; Consensus: very good.

3) Patients with second pneumothorax should have an appropriate surgical procedure according to their clinical condition and local expertise. Grade: C; Quality: low; Benefit: intermediate; Consensus: very good.

4) When transplantation is considered, patients with a history of pleurodesis or pleurectomy should be referred to transplantation centres with experience of LAM to anticipate possible pleural complications. Grade: C; Quality: low; Benefit: intermediate; Consensus: very good.

5) A history of pleurodesis or pleurectomy should not be considered a contraindication to lung transplantation in patients with LAM. However, patients should be informed of an increased risk of perioperative pleural bleeding. Grade: C; Quality: low; Benefit: intermediate; Consensus: very good.

\section{Management of chylothorax}

Chylothorax in LAM may be almost asymptomatic or cause marked dyspnoea. The interventions used [11, 37, 81, 89-94] for the management of chylothorax in LAM should be appropriate for the size and clinical impact of the effusion, comorbid factors and local expertise [91]. A fat-free diet (with or without oral supplementation of medium-sized triglycerides) or fat-free total parenteral nutrition has been used occasionally to minimise the volume of chyle formation [95]. For small effusions, observation or thoracocentesis may be sufficient.

\section{Recommendations}

1) Patients with chylothorax may be placed on a fat-free diet, with supplementation with mid-chain triglycerides. Grade: expert opinion/C; Quality: expert opinion; Benefit: small/ weak; Consensus: very good.

2) For the treatment of symptomatic chylous pleural effusions, the decision to intervene and technique used should be 
performed on an individual basis, based on clinical evaluation including amount of chyle collected, recurrence of chylothorax, respiratory condition of the patient and consideration of future lung transplantation. Grade: expert opinion/B; Quality: expert opinion; Benefit: intermediate; Consensus: very good.

\section{Treatment and follow-up of angiomyolipoma}

Although experience is based on data from case series, both embolisation and nephron sparing surgery have been performed safely without compromising renal function both in elective cases [96, 97] and acute renal haemorrhage [98], including during pregnancy [64]. Embolisation can be performed for active bleeding, is less invasive and does not require general anaesthesia but may need to be repeated. Embolisation may be favoured over surgery in patients with bleeding angiomyolipoma, although no trials have compared the two strategies. The intervention used depends upon technical factors associated with the tumour and local expertise. When bleeding is not present, nephron sparing surgery may be preferred when a malignant lesion is suspected. Surgery with intra-operative frozen section biopsy may be considered with the option to perform conservative or radical surgery; the risk of a false diagnosis of carcinoma must be borne in mind [99]. Decisions are best made electively after screening for angiomyolipoma or in response to symptoms rather than in the setting of an acute haemorrhage, early detection of angiomyolipoma is therefore important.

\section{Recommendations}

1) Patients should be advised to seek urgent medical attention in the presence of symptoms of bleeding angiomyolipoma. Grade: B; Quality: low; Benefit: substantial; Consensus: very good.

2) Embolisation should be the first-line treatment for bleeding angiomyolipoma. Nephron sparing surgery is also acceptable dependent upon local expertise. Grade: expert opinion/B; Quality: expert opinion; Benefit: substantial; Consensus: very good.

3) Embolisation should be performed as a first line therapy of angiomyolipoma in elective cases, with nephron sparing surgery indicated where a malignant lesion cannot be excluded. Technical factors associated with the tumour blood supply and local expertise should also be taken into account. Grade: C; Quality: low; Benefit: intermediate; Consensus: very good.

\section{When is treatment of angiomyolipoma indicated in asymptomatic patients?}

The risk of bleeding is linked to angiomyolipoma size and is clinically appreciable in tumours $\geqslant 4 \mathrm{~cm}$ in diameter and where aneurysms are $\geqslant 5 \mathrm{~mm}[50,100,101]$.

\section{Recommendations}

1) Asymptomatic renal angiomyolipoma $<4 \mathrm{~cm}$ should not be treated, but should be followed by yearly ultrasound unless symptoms occur. Where ultrasound measurements are unreliable due to technical factors, CT or MRI should be performed. Grade: B; Quality: low; Benefit: substantial; Consensus: very good.
2) Renal angiomyolipomas $>4 \mathrm{~cm}$ or with renal aneurysms $>5 \mathrm{~mm}$ in diameter are at an increased risk of bleeding, and should be followed by ultrasound imaging twice yearly to evaluate growth. Treatment by embolisation or nephron sparing surgery should be considered. Grade: expert opinion/A; Quality: expert opinion; Benefit: substantial; Consensus: very good.

\section{LUNG TRANSPLANTATION FOR LAM}

LAM accounts for $1.1 \%$ of lung transplant recipients [102]. LAM compares favourably to patients transplanted for other indications [38, 88, 103, 104]. In a recent survey the actuarial survival of lung transplantation for LAM was $86 \%$ at $1 \mathrm{yr}, 76 \%$ at $3 \mathrm{yrs}$, and $65 \%$ at 5 yrs [104].

\section{Referral criteria for lung transplantation}

Due to the small number of patients treated and variable rates of decrease in lung function, firm recommendations are difficult to make. In a recent survey of patients undergoing transplantation for LAM, most had severe airway obstruction and were transplanted with a mean FEV1 of $\sim 25 \%$ and DL,CO of $27 \%$ predicted [104]. Patients should be considered for lung transplantation when they reach New York Heart Association (NYHA) functional class III or IV with severe impairment in lung function and exercise capacity $\left(V^{\prime} \mathrm{O}_{2}\right.$, max $<50 \%$ pred, hypoxaemia at rest). Transplantation in patients $>65 \mathrm{yrs}$ of age may only be considered exceptionally.

\section{Recommendation}

1) Patients should be considered for lung transplantation when they reach NYHA functional class III or IV with hypoxaemia at rest, severe impairment in lung function and exercise capacity $\left(V^{\prime} \mathrm{O}_{2}\right.$ max $<50 \%$ pred). Grade: A; Quality: fair; Benefit: substantial; Consensus: very good.

\section{Which type of transplantation is indicated in LAM?}

Both single, and more commonly, bilateral lung transplantations have been performed for LAM. Although a bilateral lung transplant is associated with better post-transplant lung function and a reduction in LAM-related complications there is no difference in survival between the two procedures [104, 105].

\section{Recommendation}

1) The choice of a single, or bilateral lung transplant in LAM should be determined by surgical technical factors and organ availability. Grade: B; Quality: fair; Benefit: intermediate; Consensus: very good.

\section{Special considerations related to lung transplantation for patients with TSC}

Patients with TSC have received successful lung transplantation for severe LAM [106, 107]. Although no TSC specific problems have been identified, patients with TSC-LAM are likely to have more comorbidities than those with sporadic LAM. The impact of these processes and their treatment require careful pre-transplant evaluation.

\section{Recommendations}

1) Patients with TSC in the context of LAM should not be precluded from lung transplantation by TSC alone. Some patients may have TSC related medical or cognitive problems 
which preclude transplantation. Grade: B; Quality: low; Benefit: substantial; Consensus: very good.

2) TSC-LAM patients should have careful multi-disciplinary assessment when being evaluated for lung transplantation. Grade: B; Quality: low; Benefit: substantial; Consensus: very good.

\section{Does the presence of an angiomyolipoma affect lung transplant suitability?}

The detection of renal angiomyolipoma in LAM is important preoperatively, as the risk of bleeding associated with a large angiomyolipoma is well established. Renal angiomyolipomas were detected in $35-38 \%$ of patients during pre-transplant assessment [107, 108]. The presence of angiomyolipoma does not increase the incidence of post-transplant renal insufficiency $[107,108]$.

\section{Recommendations}

1) Angiomyolipoma may not be a contraindication to lung transplantation but may affect transplant suitability, surgery and postoperative follow-up. Grade: B; Quality: low; Benefit: substantial; Consensus: very good.

2) The presence of renal angiomyolipoma should be sought in the preoperative assessment, and those at risk of bleeding should be treated prior to transplantation. Grade: B; Quality: low; Benefit: substantial; Consensus: very good.

\section{Should the possibility of recurrent LAM in the transplanted lung be investigated post-transplantation?}

LAM recurring in the transplanted lung of either single or bilateral lung transplant is rare and generally asymptomatic. Recurrent LAM has been identified at post mortem examination or in biopsies performed for other purposes. Recurrent LAM does not seem to affect survival post transplantation [38, 88, 104, 109-111].

\section{Recommendation}

1) Routine investigation for recurrent LAM post transplantation with biopsy should not be performed. Grade: D; Quality: low; Benefit: negative; Consensus: very good.

\section{Post-transplant immunosuppression regimen for LAM}

The same immunosuppressive regimen is used as for other indications [88, 103, 107, 112]. The morbidity resulting from long-term immunosuppression is similar for LAM and nonLAM recipients [88].

\section{Recommendation}

1) Post-transplant regimen for patients with LAM should be the same as for other indications. Grade: C; Quality: low; Benefit: intermediate; Consensus: very good.

\section{CONCLUSION}

We have generated the first international clinical guidelines for LAM. As LAM is a multisystem rare disease, this required the participation of a range of specialists from many countries, particularly Europe and the USA. The absence of a strong evidence base for this rare disease required the use of a consensus technique to provide guidelines containing the best synthesis of evidence and expert opinion. These guidelines contain the first proposal of diagnostic criteria in LAM and recommend investigations and work-up for patients, screening of groups at risk for LAM, discussion of prognosis and management. The overall aim of this document is to help patients by achieving an earlier diagnosis and better care, including in countries with differing levels of healthcare resources. The guidelines will be reviewed regularly or in real time should a major advance occur.

\section{STATEMENT OF INTEREST}

A statement of interest for S.R. Johnson and J.F. Cordier can be found at www.erj.ersjournals.com/misc/statements.dtl

\section{ACKNOWLEDGEMENTS}

The affiliations for the Co-Chairs are as follows. S.R. Johnson: Division of Therapeutics and Molecular Medicine and Respiratory Biomedical Research Unit, University of Nottingham, UK; J.F. Cordier: Reference Center for Rare Pulmonary Diseases, Claude Bernard University, University of Lyon, Lyon, France.

The affiliations for the Core Panel are as follows. R. Lazor: Reference Center for Rare Pulmonary Diseases, Claude Bernard University, University of Lyon, Lyon, France and Clinic for Interstitial and Rare Lung Diseases, Dept of Respiratory Medicine, Centre Hospitalier Universitaire Vaudois, Lausanne, Switzerland; V. Cottin: Reference Center for Rare Pulmonary Diseases, Claude Bernard University, University of Lyon, Lyon, France; U. Costabel: Pneumologie/ Allergologie, Ruhrlandklinik, Universitätsklinikum Essen, Germany; S. Harari: Unità di Pneumologia, Ospedale San Giuseppe AFAR, Milan, Italy.

The affiliations for the Consultant Panel are as follows. M. ReynaudGaubert: Division of Pulmonary Medicine and Thoracic Surgery, Sainte Marguerite University Hospital, Marseille, France; A. Boehler: Pulmonary Medicine and Lung Transplant Program, University Hospital, Zurich, Switzerland; M. Brauner: Service de Radiologie, Hôpital Avicenne, Université Paris, Bobigny, France; H. Popper: Institute of Pathology, University of Graz, Graz, Austria; F. Bonetti: Policlinico B. Roma, Universita di Verona, Verona, Italy; C. Kingswood: Royal Sussex Country Hospital, Brighton, UK.

The Review panel (affiliations are listed in the online supplement; www.erj.ersjournals.com) are as follows. C. Albera, J. Bissler, D. Bouros, P. Corris, S. Donnelly, C. Durand, J. Egan, J.C. Grutters, U. Hodgson, G. Hollis, M. Korzeniewska-Kosela, J. Kus, J. Lacronique, J.W. Lammers, F. McCormack, A.C. Mendes, J. Moss, A. Naalsund, W. Pohl, E. Radzikowska, C. Robalo-Cordeiro, O. Rouvière, J. Ryu, M. Schiavina, A.E. Tattersfield, W. Travis, P. Tukiainen, T. Urban, D. Valeyre, G.M. Verleden.

We thank M-C. Thévenet (Reference Centre for Rare Pulmonary Diseases, Lyon, France) for her invaluable help at all stages of the production of the Guidelines.

This work is dedicated to the memory of M. Gonsalves, President of France Lymphangioleiomyomatosis (FLAM).

\section{REFERENCES}

1 Johnson S. Lymphangioleiomyomatosis: clinical features, management and basic mechanisms. Thorax 1999; 54: 254-264.

2 Franz DN, Brody A, Meyer C, et al. Mutational and radiographic analysis of pulmonary disease consistent with lymphangioleiomyomatosis and micronodular pneumocyte hyperplasia in women with tuberous sclerosis. Am J Respir Crit Care Med 2001; 164: 661-668. 
3 Urban T, Lazor R, Lacronique J, et al. Pulmonary lymphangioleiomyomatosis. A study of 69 patients. Groupe d'Etudes et de Recherche sur les Maladies "Orphelines" Pulmonaires (GERM"'O"P). Medicine (Baltimore) 1999; 78: 321-337.

4 Johnson SR, Tattersfield AE. Decline in lung function in lymphangioleiomyomatosis: relation to menopause and progesterone treatment. Am J Respir Crit Care Med 1999; 160: 628-633.

5 Aubry MC, Myers JL, Ryu JH, et al. Pulmonary lymphangioleiomyomatosis in a man. Am J Respir Crit Care Med 2000; 162: 749-752.

6 Schiavina M, Di Scioscio V, Contini P, et al. Pulmonary lymphangioleiomyomatosis in a karyotypically normal man without tuberous sclerosis complex. Am J Respir Crit Care Med 2007; 176: 96-98.

7 Avila NA, Kelly JA, Chu SC, et al. Lymphangioleiomyomatosis: abdominopelvic CT and US findings. Radiology 2000; 216: 147-153.

8 Chu SC, Horiba K, Usuki J, et al. Comprehensive evaluation of 35 patients with lymphangioleiomyomatosis. Chest 1999; 115: 1041-1052.

9 Moss J, DeCastro R, Patronas NJ, et al. Meningiomas in lymphangioleiomyomatosis. JAMA 2001; 286: 1879-1881.

10 Johnson SR, Tattersfield AE. Clinical experience of lymphangioleiomyomatosis in the UK. Thorax 2000; 55: 1052-1057.

11 Ryu JH, Doerr $\mathrm{CH}$, Fisher SD, et al. Chylothorax in lymphangioleiomyomatosis. Chest 2003; 123: 623-627.

12 Goncharova EA, Goncharov DA, Eszterhas A, et al. Tuberin regulates p70 S6 kinase activation and ribosomal protein S6 phosphorylation. A role for the TSC2 tumor suppressor gene in pulmonary lymphangioleiomyomatosis (LAM). J Biol Chem 2002; 277: 30958-30967.

13 Kenerson H, Folpe AL, Takayama TK, et al. Activation of the mTOR pathway in sporadic angiomyolipomas and other perivascular epithelioid cell neoplasms. Human Pathology 2007; 38: 1361-1371.

14 Bissler JJ, McCormack FX, Young LR, et al. Sirolimus for angiomyolipoma in tuberous sclerosis complex or lymphangioleiomyomatosis. N Engl J Med 2008; 358: 140-151.

15 Davies DM, Johnson SR, Tattersfield AE, et al. Sirolimus therapy in tuberous sclerosis or sporadic lymphangioleiomyomatosis. $N$ Engl J Med 2008; 358: 200-203.

16 McCrory DC, Lewis SZ. Methodology and grading for pulmonary hypertension evidence review and guideline development. Chest 2004; 126, Suppl. 1, 11S-13S.

17 Baumann $\mathrm{MH}$, Strange $\mathrm{C}$, Heffner JE, et al. Management of spontaneous pneumothorax: An American College of Chest Physicians Delphi Consensus Statement. Chest 2001; 119: 590-602.

18 Ryu JH, Moss J, Beck GJ, et al. The NHLBI lymphangioleiomyomatosis registry: characteristics of 230 patients at enrollment. Am J Respir Crit Care Med 2006; 173: 105-111.

19 Johnson SR, Whale CI, Hubbard RB, et al. Survival and disease progression in UK patients with lymphangioleiomyomatosis. Thorax 2004; 59: 800-803.

20 Kitaichi M, Nishimura K, Itoh $\mathrm{H}$, et al. Pulmonary lymphangioleiomyomatosis: a report of 46 patients including a clinicopathologic study of prognostic factors. Am J Respir Crit Care Med 1995; 151: 527-533.

21 Taveira-DaSilva AM, Stylianou MP, Hedin CJ, et al. Decline in lung function in patients with lymphangioleiomyomatosis treated with or without progesterone. Chest 2004; 126: 1867-1874.

22 Carrington CB, Cugell DW, Gaensler EA, et al. Lymphangioleiomyomatosis. Physiologic-pathologic-radiologic correlations. Am Rev Respir Dis 1977; 116: 977-995.

23 Matsui K, Beasley MB, Nelson WK, et al. Prognostic significance of pulmonary lymphangioleiomyomatosis histologic score. Am J Surg Pathol 2001; 25: 479-484.

24 Corrin B, Liebow A, Friedman P. Pulmonary lymphangiomyomatosis. A review. Am J Pathol 1975; 79: 348-382.
25 Bonetti F, Chiodera PL, Pea M, et al. Transbronchial biopsy in lymphangiomyomatosis of the lung. HMB45 for diagnosis. Am J Surg Pathol 1993; 17: 1092-1102.

26 Matsui K, Takeda K, Yu ZX, et al. Downregulation of estrogen and progesterone receptors in the abnormal smooth muscle cells in pulmonary lymphangioleiomyomatosis following therapy. An immunohistochemical study. Am J Respir Crit Care Med 2000; 161 1002-1009.

27 Glassberg MK, Elliot SJ, Fritz J, et al. Activation of the estrogen receptor contributes to the progression of pulmonary lymphangioleiomyomatosis via MMP-induced cell invasiveness. J Clin Endocrinol Metab 2008; 93: 1625-1633.

28 Zompatori M, Poletti V, Battista G, et al. Diffuse cystic lung disease in the adult patient. Radiol Med (Torino) 2000; 99: 12-21.

29 Steagall WK, Glasgow CG, Hathaway OM, et al. Genetic and morphologic determinants of pneumothorax in lymphangioleiomyomatosis. Am J Physiol Lung Cell Mol Physiol 2007; 293: L800-L808.

30 Avila NA, Chen CC, Chu SC, et al. Pulmonary lymphangioleiomyomatosis: correlation of ventilation-perfusion scintigraphy, chest radiography, and $\mathrm{CT}$ with pulmonary function tests. Radiology 2000; 214: 441-446.

31 Lenoir S, Grenier P, Brauner MW, et al. Pulmonary lymphangiomyomatosis and tuberous sclerosis: comparison of radiographic and thin-section CT findings. Radiology 1990; 175: 329-334.

32 Muller NL, Chiles C, Kullnig P. Pulmonary lymphangiomyomatosis: correlation of $\mathrm{CT}$ with radiographic and functional findings. Radiology 1990; 175: 335-339.

33 Abbott GF, Rosado-de-Christenson ML, Frazier AA, et al. From the archives of the AFIP: lymphangioleiomyomatosis: radiologicpathologic correlation. Radiographics 2005; 25: 803-828.

34 Helenon O, Merran S, Paraf F, et al. Unusual fat-containing tumors of the kidney: a diagnostic dilemma. Radiographics 1997; 17: $129-144$

35 Roach ES, Sparagana SP. Diagnosis of tuberous sclerosis complex. J Child Neurol 2004; 19: 643-649.

36 Taveira-DaSilva AM, Hedin C, Stylianou MP, et al. Reversible airflow obstruction, proliferation of abnormal smooth muscle cells, and impairment of gas exchange as predictors of outcome in lymphangioleiomyomatosis. Am J Respir Crit Care Med 2001; 164: 1072-1076.

37 Taylor JR, Ryu J, Colby TV, et al. Lymphangioleiomyomatosis. Clinical course in 32 patients. N Engl J Med 1990; 323: 1254-1260.

38 Boehler A, Speich R, Russi EW, et al. Lung transplantation for lymphangioleiomyomatosis. N Engl J Med 1996; 335: 1275-1280.

39 Taveira-DaSilva AM, Stylianou MP, Hedin CJ, et al. Maximal oxygen uptake and severity of disease in lymphangioleiomyomatosis. Am J Respir Crit Care Med 2003; 168: 1427-1431.

40 ATS Statement: Guidelines for the Six-Minute Walk Test. Am J Respir Crit Care Med 2002; 166: 111-117.

41 Costello LC, Hartman TE, Ryu JH. High frequency of pulmonary lymphangioleiomyomatosis in women with tuberous sclerosis complex. Mayo Clin Proc 2000; 75: 591-594.

42 Moss J, Avila NA, Barnes PM, et al. Prevalence and clinical characteristics of lymphangioleiomyomatosis (LAM) in patients with tuberous sclerosis complex. Am J Respir Crit Care Med 2001; 164: 669-671.

43 Castro M, Shepherd CW, Gomez MR, et al. Pulmonary tuberous sclerosis. Chest 1995; 107: 189-195.

44 Kim NR, Chung MP, Park CK, et al. Pulmonary lymphangioleiomyomatosis and multiple hepatic angiomyolipomas in a man. Pathology International 2003; 53: 231-235.

45 Casper KA, Donnelly LF, Chen B, et al. Tuberous sclerosis complex: renal imaging findings. Radiology 2002; 225: 451-456.

46 Ewalt DH, Sheffield E, Sparagana SP, et al. Renal lesion growth in children with tuberous sclerosis complex. J Urol 1998; 160: 141-145. 
47 Weiner DM, Ewalt DH, Roach ES, et al. The tuberous sclerosis complex: a comprehensive review. J Am Coll Surg 1998; 187: 548-561.

48 L'Hostis H, Deminiere C, Ferriere JM, et al. Renal angiomyolipoma: a clinicopathologic, immunohistochemical, and follow-up study of 46 cases. Am J Surg Pathol 1999; 23: 1011-1020.

49 Nelson CP, Sanda MG. Contemporary diagnosis and management of renal angiomyolipoma. J Urol 2002; 168: 1315-1325.

50 Steiner MS, Goldman SM, Fishman EK, et al. The natural history of renal angiomyolipoma. J Urol 1993; 150: 1782-1786.

51 Kennelly MJ, Grossman HB, Cho KJ. Outcome analysis of 42 cases of renal angiomyolipoma. J Urol 1994; 152: 1988-1991.

52 Dickinson $\mathrm{M}$, Ruckle $\mathrm{H}$, Beaghler $\mathrm{M}$, et al. Renal angiomyolipoma: optimal treatment based on size and symptoms. Clin Nephrol 1998; 49: 281-286.

53 Lazor R, Valeyre D, Lacronique J, et al. Low initial KCO predicts rapid FEV1 decline in pulmonary lymphangioleiomyomatosis. Respir Med 2004; 98: 536-541.

54 Cohen MM, Pollock-BarZiv S, Johnson SR. Emerging clinical picture of lymphangioleiomyomatosis. Thorax 2005; 60: 875-879.

55 Almoosa KF, Ryu JH, Mendez J, et al. Management of pneumothorax in lymphangioleiomyomatosis: effects on recurrence and lung transplantation complications. Chest 2006; 129: 1274-1281.

56 Fujimoto M, Ohara N, Sasaki H, et al. Pregnancy complicated with pulmonary lymphangioleiomyomatosis: case report. Clin Exp Obstet Gynecol 2005; 32: 199-200.

57 Brunelli A, Catalini G, Fianchini A. Pregnancy exacerbating unsuspected mediastinal lymphangioleiomyomatosis and chylothorax. Int J Gynaecol Obstet 1996; 52: 289-290.

58 McLoughlin L, Thomas G, Hasan K. Pregnancy and lymphangioleiomyomatosis: anaesthetic management. Int J Obstet Anesth 2003; 12: 40-44.

59 Yockey CC, Riepe RE, Ryan K. Pulmonary lymphangioleiomyomatosis complicated by pregnancy. Kans Med 1986; 87, 277-278: 293.

60 Warren SE, Lee D, Martin V, et al. Pulmonary lymphangiomyomatosis causing bilateral pneumothorax during pregnancy. Ann Thorac Surg 1000; 55: 998-1000.

61 Cohen MM, Freyer AM, Johnson SR. Pregnancy experiences among women with lymphangioleiomyomatosis. Respir Med 2009; 103: 766-772.

62 Raft J, Lalot JM, Meistelman C, et al. [Renal angiomyolipoma rupture during pregnancy.] Gynecol Obstet Fertil 2006; 34 917-919.

63 Storm DW, Mowad JJ. Conservative management of a bleeding renal angiomyolipoma in pregnancy. Obstet Gynecol 2006; 107: 490-492.

64 Morales JP, Georganas M, Khan MS, et al. Embolization of a bleeding renal angiomyolipoma in pregnancy: case report and review. Cardiovasc Intervent Radiol 2005; 28: 265-268.

65 Mascarenhas R, McLaughlin P. Haemorrhage from angiomyolipoma of kidney during pregnancy-a diagnostic dilemma. Ir Med J 2001; 94: 83-84.

66 Yano S. Exacerbation of pulmonary lymphangioleiomyomatosis by exogenous oestrogen used for infertility treatment. Thorax 2002; 57: 1085-1086.

67 Shen A, Iseman MD, Waldron JA, et al. Exacerbation of pulmonary lymphangioleiomyomatosis by exogenous estrogens. Chest 1987; 91: 782-785.

68 Wilson AM, Slack HL, Soosay SA, et al. Lymphangioleiomyomatosis. A series of three case reports illustrating the link with high oestrogen states. Scott Med J 2001; 46: 150-152.

69 Oberstein EM, Fleming LE, Gomez-Marin O, et al. Pulmonary lymphangioleiomyomatosis (LAM): examining oral contraceptive pills and the onset of disease. J Women's Health 2003; 12: 81-85.
70 Pollock-BarZiv S, Cohen MM, Downey GP, et al. Air travel in women with lymphangioleiomyomatosis. Thorax 2007; 62: 176-180.

71 Rehabilitation BTSSoCs-coP. BTS statement on pulmonary rehabilitation. Thorax 2001; 56: 827-834.

72 Managing stable COPD. Thorax 2004; 59: Suppl. 1, i39-i130.

73 Taveira-DaSilva AM, Stylianou MP, Hedin CJ, et al. Bone mineral density in lymphangioleiomyomatosis. Am J Respir Crit Care Med 2005; 171: 61-67.

74 Adamson D, Heinrichs WL, Raybin DM, et al. Successful treatment of pulmonary lymphangiomyomatosis with oophorectomy and progesterone. Am Rev Respir Dis 1985; 132: 916-921.

75 Anker N, Francis D, Viskum K. [2 cases of lymphangioleiomyomatosis treated by hormonal manipulation.] Ugeskr Laeger 1993; 155: 2354-2356.

76 Banner AS, Carrington CB, Emory WB, et al. Efficacy of oophorectomy in lymphangioleiomyomatosis and benign metastasizing leiomyoma. N Engl J Med 1981; 305: 204-209.

77 Itoi K, Kuwabara M, Okubo K, et al. [A case of pulmonary lymphangiomyomatosis treated with bilateral oophorectomy and methyl-progesterone-acetate.] Nihon Kyobu Shikkan Gakkai Zasshi 1993; 31: 1146-1150.

78 Kanbe A, Hajiro K, Adachi Y, et al. Lymphangiomyomatosis associated with chylous ascites and high serum CA-125 levels: a case report. Jpn J Med 1987; 26: 237-242.

79 Brock ET, Votto JJ. Lymphangioleiomyomatosis: treatment with hormonal manipulation. N Y State J Med 1986; 86: 533-536.

80 Klein M, Krieger O, Ruckser R, et al. Treatment of lymphangioleiomyomatosis by ovariectomy, interferon alpha $2 \mathrm{~b}$ and tamoxifen-a case report. Arch Gynecol Obstet 1992; 252: 99-102.

81 Svendsen TL, Viskum K, Hansborg N, et al. Pulmonary lymphangioleiomyomatosis: a case of progesterone receptor positive lymphangioleiomyomatosis treated with medroxyprogesterone, oophorectomy and tamoxifen. $\mathrm{Br} J$ Dis Chest 1984; 78: 264-271.

82 Tomasian A, Greenberg MS, Rumerman H. Tamoxifen for lymphangioleiomyomatosis. $N$ Engl J Med 1982; 306: 745-746.

83 de la Fuente J, Paramo C, Roman F, et al. Lymphangioleiomyomatosis: unsuccessful treatment with luteinizing-hormone-releasing hormone analogues. Eur J Med 1993; 2: 377-378.

84 Desurmont S, Bauters C, Copin MC, et al. [Treatment of pulmonary lymphangioleiomyomatosis using a GnRH agonist.] Rev Mal Respir 1996; 13: 300-304.

85 Rossi GA, Balbi B, Oddera S, et al. Response to treatment with an analog of the luteinizing-hormone-releasing hormone in a patient with pulmonary lymphangioleiomyomatosis. Am Rev Respir Dis 1991; 143: 174-176.

86 Harari S, Cassandro R, Chiodini J, et al. Effect of a gonadotrophin-releasing hormone analogue on lung function in lymphangioleiomyomatosis. Chest 2008; 133: 448-454.

87 Detterbeck FC, Egan TM, Mill MR. Lung transplantation after previous thoracic surgical procedures. Ann Thorac Surg 1995; 60: 139-143.

88 Pechet TT, Meyers BF, Guthrie TJ, et al. Lung transplantation for lymphangioleiomyomatosis. J Heart Lung Transplant 2004; 23: 301-308.

89 Morimoto N, Hirasaki S, Kamei T, et al. Pulmonary lymphangiomyomatosis (LAM) developing chylothorax. Intern Med 2000; 39: 738-741.

90 Christodoulou M, Ris H-B, Pezzetta E. Video-assisted right supradiaphragmatic thoracic duct ligation for non-traumatic recurrent chylothorax. Eur J Cardiothorac Surg 2006; 29: 810-814.

91 Avila NA, Dwyer AJ, Rabel A, et al. CT of pleural abnormalities in lymphangioleiomyomatosis and comparison of pleural findings after different types of pleurodesis. AJR Am J Roentgenol 2006; 186: 1007-1012. 
92 Druelle S, Aubry P, Levi-Valensi P. [Pulmonary lymphangiomyomatosis: a 3-year follow-up of medroxyprogesterone acetate therapy. Apropos of a case.] Rev Pneumol Clin 1995; 51: 284-287.

93 Zanella A, Toppan P, Nitti D, et al. Pulmonary lymphangioleiomyomatosis: a case report in postmenopausal woman treated with pleurodesis and progesterone (medroxyprogesterone acetate). Tumori 1996; 82: 96-98.

94 Wójcik P, Otto T, Jagiełło R, et al. Use of pleuro-peritoneal shunt in the treatment of chronic chylothorax. Pneumonol Alergol Pol 1998; 66: 473-479.

95 Calvo E, Amarillas L, Mateos MA, et al. Lymphangioleiomyomatosis, chylous ascites, and diet. Dig Dis Sci 1996; 41: 591-593.

96 Hamlin JA, Smith DC, Taylor FC, et al. Renal angiomyolipomas: long-term follow-up of embolization for acute hemorrhage. Can Assoc Radiol J 1997; 48: 191-198.

97 Williams JM, Racadio JM, Johnson ND, et al. Embolization of renal angiomyolipomata in patients with tuberous sclerosis complex. Am J Kidney Dis 2006; 47: 95-102.

98 Igarashi A, Masuyama T, Watanabe K, et al. Long-term result of the transcatheter arterial embolization for ruptured renal angiomyolipoma. Nippon Hinyokika Gakkai Zasshi 2002; 93: 702-706.

99 Bender B, Yunis E. The pathology of tuberous sclerosis. Pathol Апnи 1982; 17: 339-382.

100 van Baal JG, Smits NJ, Keeman JN, et al. The evolution of renal angiomyolipomas in patients with tuberous sclerosis. J Urol 1994; 152: $35-38$

101 Yamakado K, Tanaka N, Nakagawa T, et al. Renal angiomyolipoma: relationships between tumor size, aneurysm formation, and rupture. Radiology 2002; 225: 78-82.

102 Trulock EP. Lung transplantation: special considerations and outcome in LAM. In: Moss J, ed. LAM and other Diseases
Characterised by Smooth Muscle Proliferation. New York, Marcel Dekker, 1999; pp. 65-78.

103 Pigula FA, Griffith BP, Zenati MA, et al. Lung transplantation for respiratory failure resulting from systemic disease. Ann Thorac Surg 1997; 64: 1630-1634.

104 Kpodonu J, Massad MG, Chaer RA, et al. The US experience with lung transplantation for pulmonary lymphangioleiomyomatosis. J Heart Lung Transplant 2005; 24: 1247-1253.

105 Boehler A. Lung transplantation for cystic lung diseases: lymphangioleiomyomatosis, histiocytosis $\mathrm{x}$, and sarcoidosis Semin Respir Crit Care Med 2001; 22: 509-516.

106 Benden C, Rea F, Behr J, et al. Lung transplantation for lymphangioleiomyomatosis: the European experience. $J$ Heart Lung Transplant 2009; 28: 1-7.

107 Reynaud-Gaubert M, Mornex JF, Mal H, et al. Lung transplantation for lymphangioleiomyomatosis: the French experience. Transplantation 2008; 86: 515-520.

108 Collins J, Muller NL, Kazerooni EA, et al. Lung transplantation for lymphangioleiomyomatosis: role of imaging in the assessment of complications related to the underlying disease. Radiology 1999; 210: 325-332.

109 Nine JS, Yousem SA, Paradis IL, et al. Lymphangioleiomyomatosis: recurrence after lung transplantation. J Heart Lung Transplant 1994; 13: 714-719.

110 Bittmann I, Rolf B, Amann G, et al. Recurrence of lymphangioleiomyomatosis after single lung transplantation: New insights into pathogenesis. Hum Pathol 2003; 34: 95-98.

111 Karbowniczek M, Astrinidis A, Balsara BR, et al. Recurrent lymphangiomyomatosis after transplantation: genetic analyses reveal a metastatic mechanism. Am J Respir Crit Care Med 2003, 167: 976-982.

112 Benden C, Boehler A, Faro A. Pediatric lung transplantation: Literature review. Pediatr Transplant 2008; 12: 266-273. 